\title{
Subtypes and symptoms of fecal incontinence in the Dutch population: a cross-sectional study
}

\author{
Maxime M. van Meegdenburg ${ }^{1} \cdot$ Rob J. Meinds $^{1} \cdot$ Monika Trzpis $^{1} \cdot$ Paul M. A. Broens ${ }^{1,2}$
}

Accepted: 4 April 2018 / Published online: 28 April 2018

(C) The Author(s) 2018

\begin{abstract}
Purpose To study the distribution of subtypes and symptoms of fecal incontinence in the general Dutch population. Methods We performed a cross-sectional study in a representative sample of the general Dutch population. All respondents $(N=$ 1259) completed the Groningen Defecation and Fecal Continence questionnaire. We assigned the respondents to a so-called healthy subgroup $(n=1008)$ and a comorbidity subgroup $(n=251)$. The latter subgroup comprised the respondents who reportedly suffered from chronic diseases and who had undergone surgery known to influence fecal continence. We defined fecal incontinence according to the Rome IV criteria.

Results The combination of urge fecal incontinence and soiling was the most frequent form of fecal incontinence in the total study group, the "healthy" subgroup, and the comorbidity subgroup (49.0, 47.3, and 51.5\%). Passive fecal incontinence was the least frequent form of fecal incontinence in all three groups (4.0, 5.4, and 2.2\%). The prevalence and severity of fecal incontinence was significantly higher in the comorbidity subgroup than in the "healthy" subgroup. Only in the comorbidity subgroup did the fecally incontinent respondents feel urge sensation significantly less often before defecating than their fecally continent counterparts $(16.5$ versus $48.8 \%, P<0.001)$.

Conclusion Urge fecal incontinence combined with soiling is commonest in the general Dutch population. Chronic diseases and bowel and pelvic surgery both increase and aggravate fecal incontinence.
\end{abstract}

Keywords Anorectal disorder $\cdot$ Population characteristics $\cdot$ Rectal diseases $\cdot$ Accidental bowel leakage

\section{Introduction}

Fecal incontinence (FI) can be a devastating disease and it may have a significant impact on people's quality of life and healthcare costs. [1-4] Generally, FI is defined as involuntary loss of feces at least once a month. Different subtypes of FI are recognized and include the type of leakage (for example,

Electronic supplementary material The online version of this article (https://doi.org/10.1007/s00384-018-3051-5) contains supplementary material, which is available to authorized users.

Maxime M. van Meegdenburg

m.van.meegdenburg02@umcg.nl

1 Department of Surgery, Anorectal Physiology Laboratory, University Medical Center Groningen, University of Groningen, PO Box 30 001, 9700 RB Groningen, the Netherlands

2 Department of Surgery, Division of Pediatric Surgery, University of Groningen, University Medical Center Groningen, Groningen, the Netherlands soiling, urge FI, passive FI, or combined FI) [5-7]. In a recent systematic review, $\mathrm{Ng}$ and colleagues reported that the median prevalence of FI in representative samples of the general populations of amongst others Australia, New Zealand, the USA, the UK, and Canada is $7.3 \%$ and ranges from 2.0 to $13.2 \%$ [8]. These findings are in accordance with our study that showed a $7.9 \%$ prevalence of FI in the Netherlands [9]. To date, only a few studies investigated the prevalence of the subtypes of FI, all with varying results [10-12].

Variability in the prevalence of FI can be explained by several factors. Most important are the different diagnostic criteria for FI and its subtypes. The heterogeneity of data collection methods are also known to influence the prevalence of FI. For example, data were collected by questionnaires, telephonic interviews, and digital surveys [8]. Moreover, most of the studies on the prevalence of the subtypes of FI were performed in patient populations rather than in a sample representing the general population. Finally, the heterogeneity in demographic characteristics might influence the prevalence of FI, because age is considered to have a strong influence on 
the prevalence of FI $[4,8]$. The higher prevalence of FI in the elderly in comparison to younger age groups may be caused by an increase in comorbidities, such as impaired mobility, which makes it more difficult to reach the toilet in time.

Our primary objective therefore was to examine the prevalence of the subtypes of FI in the general Dutch population. Secondarily, we aimed to investigate the distribution of the symptoms of FI. We also studied the influence on the distribution of the subtypes and symptoms of FI of somatic disorders and types of surgery that known to affect fecal continence.

\section{Materials and methods}

\section{Study design}

Between 1 September and 1 November 2015, we examined a cross section of the adult Dutch population using the Groningen Defecation and Fecal Continence (DeFeC) questionnaire (supplemental file) [13]. Data from the general Dutch population were collected by Survey Sampling International. This company, based in Rotterdam, the Netherlands, specializes in conducting surveys. They drew a population-based sample from their database and these people were sent a link that enabled them to fill out the DeFeC questionnaire digitally. Of the 3031 respondents who started filling out the questionnaire, $1642(54.2 \%)$ filled it out completely. From the completed questionnaires, Survey Sampling International randomly selected 1259 (76.7\%) respondents to obtain a representative cohort that was equally distributed across sex, region, and age in accordance with the population pyramid of the Netherlands (supplied by Statistics Netherlands) [14]. These 1259 respondents constituted our total study group of the general Dutch population.

Besides, we assigned each of the respondents in the total study group to either a "healthy" subgroup or a comorbidity subgroup. The comorbidity subgroup comprised 251 respondents who reported a history of bowel or pelvic surgery or who suffered from somatic diseases that could have influenced fecal continence, including intestinal resection, perianal fistula, anal sphincter surgery, hemorrhoid, prostate or rectal prolapse surgery, inflammatory bowel diseases, diabetes, cerebral stroke, neurological disorders (for example, spinal cord injury or multiple sclerosis), slow transit constipation, or congenital disorders (for example, anorectal malformation, Hirschsprung's disease, sacrococcygeal teratoma, or spina bifida). The "healthy" subgroup comprised the remaining 1008 respondents.

\section{Definitions of demographic characteristics}

A respondent's highest level of education was classified as primary (primary or middle school), secondary (high school or vocational education), or tertiary (university or college). Respondents who lived in a small village or a city with a maximum of 50,000 inhabitants were classified as living in a rural environment, while respondents who lived in a city of more than 50,000 inhabitants were classified as living in an urban environment. Respondents' body mass indices (BMIs, $\mathrm{kg} / \mathrm{m}^{2}$ ) were classified according to WHO guidelines: underweight $\left(<18.5 \mathrm{~kg} / \mathrm{m}^{2}\right)$, normal weight $\left(18.5\right.$ to $\left.25 \mathrm{~kg} / \mathrm{m}^{2}\right)$, overweight (25 to $\left.30 \mathrm{~kg} / \mathrm{m}^{2}\right)$, or obese $\left(>30 \mathrm{~kg} / \mathrm{m}^{2}\right)$.

\section{Definitions of defecation disorders}

We defined FI according to the Rome IV criteria, namely recurrent uncontrolled passage of fecal material at least several times a month for the past 6 months [15]. In both the "healthy" subgroup and the comorbidity subgroup, we classified the respondents with FI according to the type of FI they had. Soiling was defined as accidental passage of small amounts of feces (that is, staining or soiling of underpants). Urge FI was defined as feeling a strong urge to defecate and being unable to reach the toilet in time to prevent FI, having to rush to the toilet to prevent FI, or the inability to postpone defecation for more than $5 \mathrm{~min}$ after feeling urge sensation. Passive FI was defined as accidental passage of large amounts of solid stool in the absence of urge sensation. To determine the severity of FI, we calculated the Vaizey incontinence score, [16] and the Continence Grading Scale as described by Jorge and Wexner [17].

All medical information was reported by the respondents themselves and because they filled in the questionnaires anonymously we could not review their medical records.

\section{Statistical analysis}

Data were analyzed with SPSS for Windows, Version 23.0 (IBM SPSS Statistics, IBM Corporation, Armonk, NY). We reported median, minimum, and maximum values. Comparisons between the "healthy" subgroup and the comorbidity subgroup were performed using the Fisher exact and the Mann-Whitney tests. Statistical significance was defined as $P \leq 0.05$.

\section{Results}

The total study group comprised 1259 respondents with a median age of 49 years (range 18 to 85 years). The respondents in the "healthy" subgroup were significantly younger than the respondents in the comorbidity subgroup (48 years versus 57 years, $P<0.001$ ) and it consisted of significantly more women than the comorbidity subgroup (55.8 versus $47.0 \%, P=0.013)$. Other demographic characteristics of the included respondents are presented in Table 1. 
Table 1 Respondent characteristics

\begin{tabular}{|c|c|c|c|c|}
\hline & $\begin{array}{l}\text { Total study group } \\
N(\%)\end{array}$ & $\begin{array}{l}\text { "Healthy" subgroup } \\
n(\%)\end{array}$ & $P$ & $\begin{array}{l}\text { Comorbidity subgroup } \\
n(\%)\end{array}$ \\
\hline Overall & $1259(100)$ & $1008(100)$ & & $251(100)$ \\
\hline Sex & & & 0.013 & \\
\hline Men & $579(46.0)$ & $446(44.2)$ & & $133(53.0)$ \\
\hline Women & $680(54.0)$ & $562(55.8)$ & & $118(47.0)$ \\
\hline Educational level & & & 0.196 & \\
\hline Primary & $260(20.7)$ & $198(19.6)$ & & $62(24.7)$ \\
\hline Secondary & $505(40.1)$ & $407(40.3)$ & & $98(39.0)$ \\
\hline Tertiary & $494(39.2)$ & $403(40.0)$ & & $91(36.3)$ \\
\hline Residence & & & 0.711 & \\
\hline Rural & $436(34.6)$ & 352 (34.9) & & $84(33.5)$ \\
\hline Urban & $823(65.4)$ & $656(65.1)$ & & $167(66.5)$ \\
\hline Body mass index & & & $<0.001$ & \\
\hline Underweight & $26(2.1)$ & $24(2.4)$ & & $2(0.8)$ \\
\hline Normal weight & $549(43.6)$ & $463(45.9)$ & & $86(34.3)$ \\
\hline Overweight & $423(33.6)$ & $331(32.8)$ & & $92(36.7)$ \\
\hline Obese & $261(20.7)$ & $190(18.8)$ & & $71(28.3)$ \\
\hline
\end{tabular}

\section{Distribution of subtypes of FI and severity of FI}

In the total study group, the prevalence of FI was $7.9 \%$. The prevalence of FI was significantly lower in the "healthy" subgroup than in the comorbidity subgroup (5.5 versus $17.9 \%$, $P<0.001)$. As depicted in Fig. 1, the combination of soiling and urge FI was most common in the total study group, followed by the "healthy" subgroup and the comorbidity subgroup (49.0, 47.3, and 51.1\%). Least common in all three groups was passive FI (4.0, 5.4, and 2.2\%, respectively).

The median Wexner score and the median Vaizey score in the total study group with FI was 8 (range 1 to 20) and 11 (range 3 to 20), respectively. As illustrated in Fig. 2, the median Wexner and Vaizey scores were higher in the fecally incontinent respondents in the comorbidity subgroup than in the fecally incontinent respondents in the "healthy" subgroup (9 versus $7, P=0.086$ and 12 versus $10, P=0.008$ ). In all three groups, the Wexner and Vaizey scores did not differ significantly as regards sex or age (data not shown).

\section{Characteristics of FI}

We also asked the FI respondents about the amount of stool loss, whether stool was lost while awake or during sleep, and the frequency of stool loss. Most of the respondents with FI in the total group and "healthy" subgroup lost small amounts of stool, while most of the respondents with FI in the comorbidity subgroup needed to change their underwear $(54,64$, and $44 \%$, Fig. 3a). In all three groups, stool was most often lost while awake (68,76, and 58\%, Fig. 3b). Respondents in the comorbidity subgroup suffered from FI while asleep significantly more often than did respondents in the "healthy" subgroup (24 versus $7 \% P=0.048$ ). Lastly, loss of small

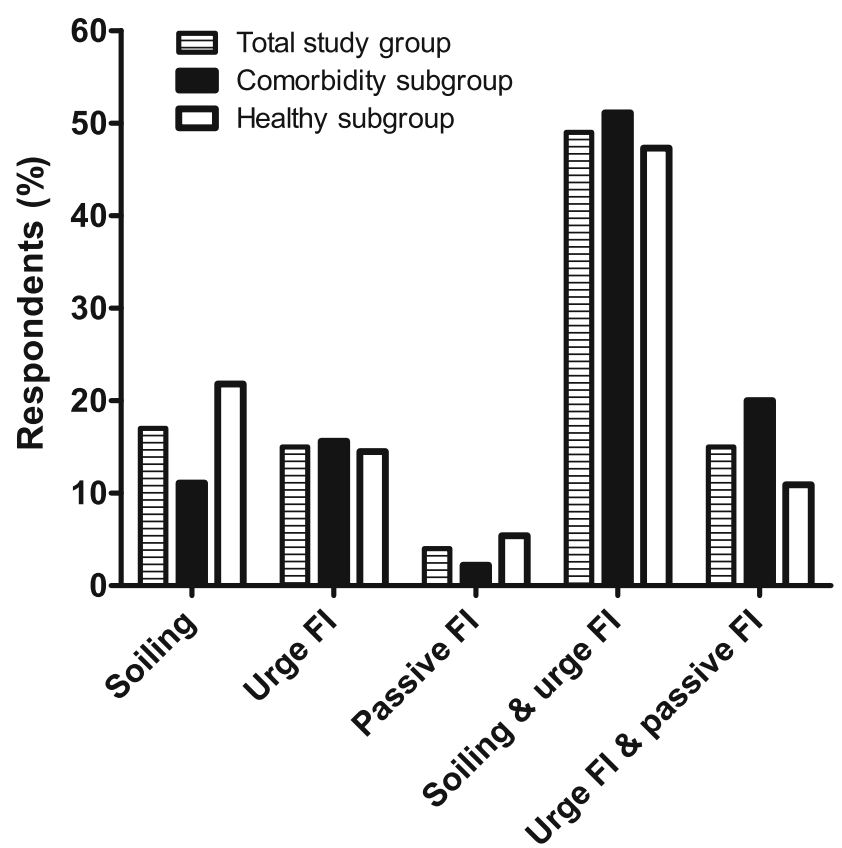

Fig. 1 The subtypes of fecal incontinence (FI) in the total study group, the comorbidity subgroup, and the "healthy" subgroup. In the total study group and in the "healthy" subgroup, most respondents suffered from the combination of soiling and urge FI (49.0 and 47.3\%), followed by soiling alone (17.0 and 21.8\%), urge FI alone (15.0 and 14.5\%), the combination of urge FI and passive FI (15.0 and 10.9\%), and passive FI alone (4.0 and $5.4 \%)$. In the comorbidity subgroup, most respondents suffered from the combination of soiling and urge FI (51.1\%), followed by the combination of urge FI and passive FI (20.0\%), urge FI alone (15.6\%), soiling alone (11.1\%), and passive FI alone (2.2\%) 
Fig. 2 The Wexner and Vaizey scores in the total study group, the comorbidity subgroup, and the "healthy" subgroup. a The median Wexner score was 8 (range 1 to 20) in the total group and it tended to be lower in the "healthy" subgroup compared to the comorbidity subgroup (7 versus $9, P=0.086$ ). The black dots in the total study group represent outliers. b The median Vaizey score was 11.0 (range 3 to 20 ) in the total group and was significantly lower in the 'healthy' subgroup than in the comorbidity subgroup (10 versus $12, P=0.008)$
A Wexner score

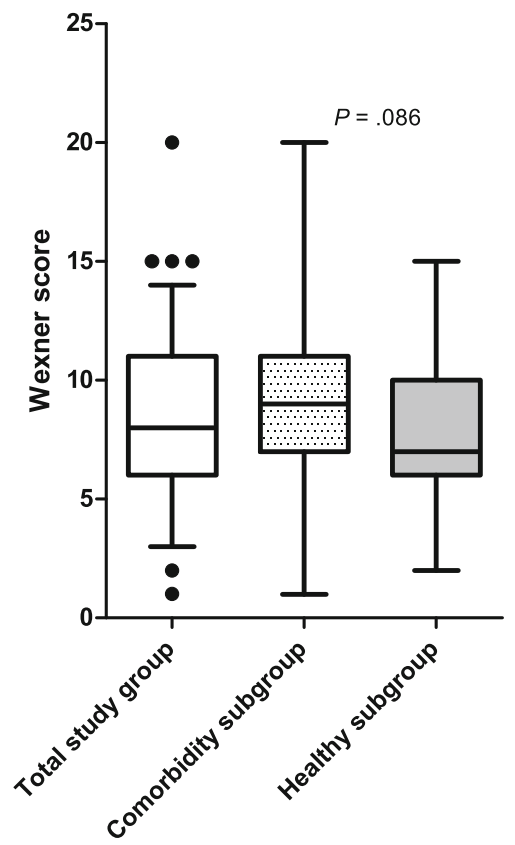

B Vaizey score

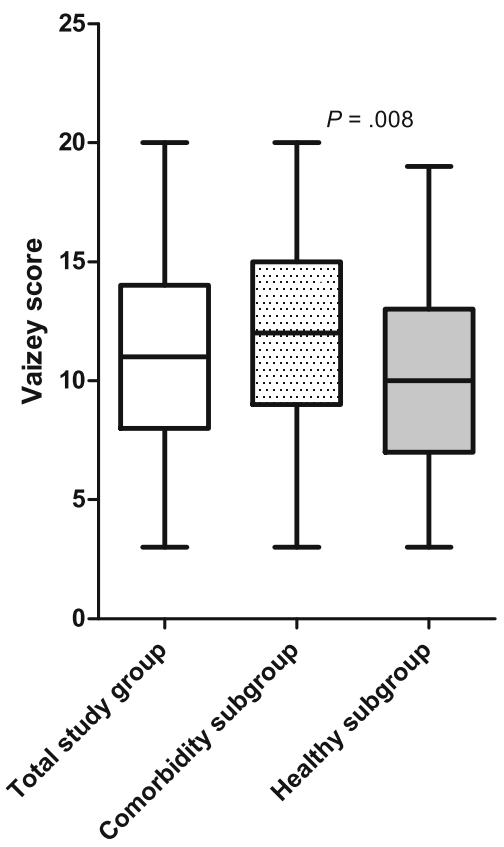

amounts of stool one to three times a month was seen in both groups, while the loss of larger amounts of stool was less frequent (Fig. 3c).

\section{Distribution of symptoms associated with FI and use of medication}

First, we analyzed whether the respondents with FI used stool softeners (laxatives) or stool hardeners (antidiarrheals, Table 2). In all three groups, we found that respondents with FI used laxatives and antidiarrheals significantly more often than respondents without FI.

Second, we analyzed the distribution of the following symptoms of FI: decreased ability to feel urge sensation before defecating, decreased ability to discriminate between different types of stool, the inability to control the bowels for a certain length of time after feeling urge sensation, experiencing fecal urgency at least once a month, and feeling abdominal pain at least once a month (Table 2). In the comorbidity subgroup, respondents who suffered from FI felt urge sensation before defecating significantly less often in comparison to fecally continent respondents (48.8 versus $16.5 \%, P<0.001$ ). In the "healthy" subgroup, we found no significant difference between respondents who did or did not suffer from FI regarding the feeling of urge sensation before defecating (30.9 versus $25.0 \%, P=0.329)$. In all three groups, the respondents who suffered from FI were less able to discriminate between different stool types and experienced fecal urgency more often than the fecally continent respondents. Additionally, once the respondents with FI reached urge sensation, they were significantly less able to control their bowels for more than $5 \mathrm{~min}$.

\section{Discussion}

We demonstrated that in the general Dutch population the combination of soiling and urge FI was the most common subtype of FI, while passive FI was least common. Respondents in the comorbidity subgroup suffered from FI significantly more often and they suffered from a more severe form of FI than respondents in the "healthy" subgroup. The fact that respondents with comorbidities experienced FI was in itself not surprising. What was striking, however, was that the theoretically "healthy" group appeared not to be so healthy after all, considering the relatively high prevalence of FI in this subgroup. Apparently, FI occurs more often than thought, even in "healthy" subjects.

Why soiling and urge FI occur so often in the Dutch population is unknown, because the exact mechanisms underlying these subtypes of FI has not yet been determined. The high prevalence of soiling, however, may be caused by constipation, soiling is a known consequence of constipation. Recently, we demonstrated that the prevalence of constipation is as high as $24.5 \%$ in the general Dutch population [13]. Urge FI can be a result of a diminished conscious contraction of the external anal sphincter caused by pudendal neuropathy, which in turn may be caused by constipation, even though it may also be the result of factors such as pelvic surgery or somatic diseases.

The low prevalence of passive FI might be explained by our recent finding with regard to the underlying pathophysiology of passive FI $[18,19]$. We found that passive FI can be the result of a diminished unconscious contraction of the external anal sphincter as seen in patients with a non-functioning anal-external sphincter continence reflex (AESCR). 


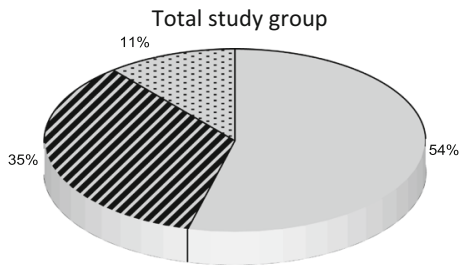

Small amount (size of a coin)
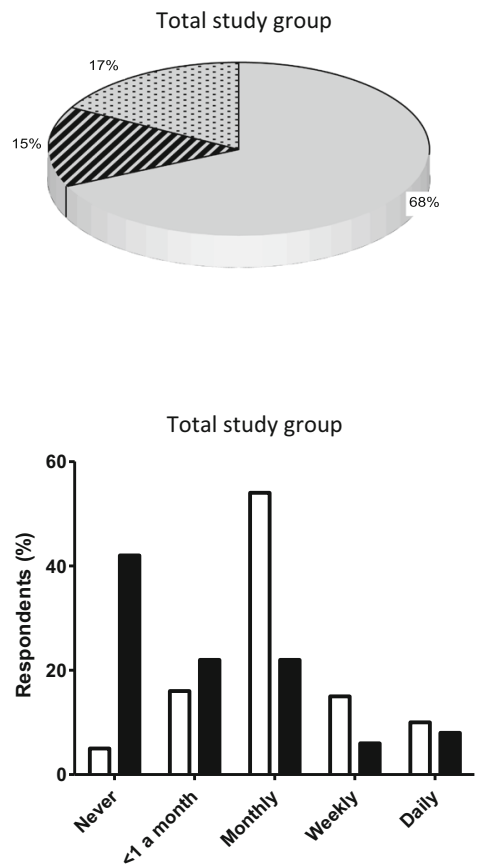

Fig. 3 The amount of stool lost, the moment of stool loss, and the frequency of fecal incontinence (FI) in the total study group, the comorbidity subgroup, and the "healthy" subgroup. a While most respondents in the total study group and "healthy" subgroup lost a negligible amount of stool, most respondents in the comorbidity subgroup lost an amount that necessitated a change of underwear. In all three groups, only a few respondents lost a larger amount of stool that necessitated a change of

Furthermore, we found that unconscious contraction of the external anal sphincter is not affected by aging, in contrast to conscious contraction, which decreases with aging. [19] Thus, the elderly suffer from urge FI more often than from passive FI, thus explaining the low prevalence of passive FI in the Dutch population.

A few other studies also addressed the distribution of the subtypes of FI [7, 10, 11, 20]. In our opinion, however, our results cannot be compared with the results reported by these studies on account of differences in study methods. Most importantly, we included a random selection of the general population, while the other studies were limited to patients suffering from FI. Moreover, they used different definitions for the subtypes of FI.

We described the symptoms experienced by the respondents with FI. One of our findings in the comorbidity

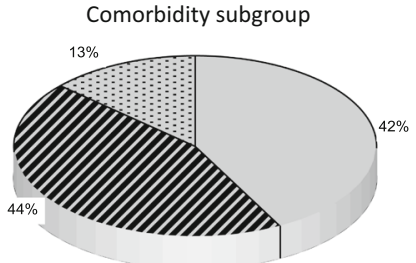

Needed change of underwear and trousers
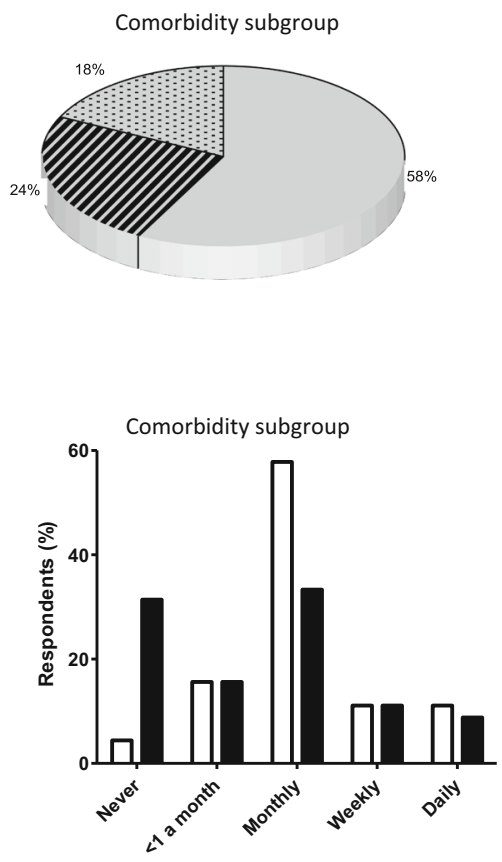

FI - large amount

outerwear. b In all three groups, most respondents only suffered from FI while they were awake. Respondents in the comorbidity subgroup suffered from FI more often while awake and during sleep compared to the other two groups. c In all three groups, most respondents lost small amounts of stool accidentally one to three times a month. Respondents who lost large amounts of stool, most often reported this to be less than once a month up to several times a month

subgroup was that fecally incontinent respondents felt urge sensation before defecating less often than their fecally continent counterparts. This indicates that FI in the comorbidity subgroup might be caused by sensory nerve dysfunction on account of pelvic floor surgery or comorbidities such as diabetes mellitus. Our assumption is supported by an opposite observation in the "healthy" subgroup: respondents with FI felt urge sensation before defecating comparably often as fecally continent respondents.

Furthermore, we offer two explanations for nocturnal FI reported by $24 \%$ of the respondents in the comorbidity subgroup and a remarkable $7 \%$ in the "healthy" subgroup. First, in our clinical practice, we see patients with severe forms of dyssnergic defecation who suffer from nocturnal FI. We hypothesize that they, unintentionally, withhold their stool 
Table 2 Use of medication influencing FI and symptoms of FI in the "healthy" and comorbidity subgroups

\begin{tabular}{|c|c|c|c|c|c|c|c|c|c|}
\hline & \multicolumn{3}{|c|}{ Total study group } & \multicolumn{3}{|c|}{ "Healthy” subgroup } & \multicolumn{3}{|c|}{ Comorbidity subgroup } \\
\hline & No FI $n(\%)$ & FI $n(\%)$ & $P$ & No FI $n(\%)$ & FI $n(\%)$ & $P$ & No FI $n(\%)$ & FI $n(\%)$ & $P$ \\
\hline Used laxative medication & $64(5.5)$ & $27(27.0)$ & $<0.001$ & $49(5.1)$ & $10(18.2)$ & $<0.001$ & $28(13.6)$ & $19(42.2)$ & $<0.001$ \\
\hline Used antidiarrheals medication & $8(0.7)$ & $15(15.0)$ & $<0.001$ & $6(0.6)$ & $4(7.3)$ & 0.013 & $2(1.0)$ & $13(28.9)$ & $<0.001$ \\
\hline Felt urge before defecating & & & 0.002 & & & 0.329 & & & $<0.001$ \\
\hline Yes & $887(76.5)$ & $61(61.0)$ & & $715(75.0)$ & $38(69.1)$ & & $172(83.5)$ & $23(51.1)$ & \\
\hline Sometimes & $205(17.7)$ & $31(31.0)$ & & 177 (18.6) & $11(20.0)$ & & $28(13.6)$ & $20(44.4)$ & \\
\hline No & $67(5.8)$ & $8(8.0)$ & & $61(6.4)$ & $6(10.9)$ & & $6(2.9)$ & $2(4.4)$ & \\
\hline $\begin{array}{l}\text { Could discriminate between } \\
\text { different types of stool }\end{array}$ & & & $<0.001$ & & & $<0.001$ & & & $<0.001$ \\
\hline Yes & 949 (81.9) & $39(39.0)$ & & $788(82.7)$ & $21(38.2)$ & & $161(78.2)$ & $18(40.0)$ & \\
\hline Difficult & $112(9.7)$ & $46(46.0)$ & & $79(8.3)$ & $24(43.6)$ & & $33(16.0)$ & $22(48.9)$ & \\
\hline No & $98(8.5)$ & $15(15.0)$ & & $86(9.0)$ & $10(18.2)$ & & $12(5.8)$ & $5(11.1)$ & \\
\hline $\begin{array}{l}\text { Could control bowels after urge } \\
\text { sensation for: }\end{array}$ & & & $<0.001$ & & & $<0.001$ & & & $<0.001$ \\
\hline$<1 \min$ & $90(7.8)$ & $35(35.0)$ & & $67(7.0)$ & $17(30.9)$ & & $23(11.2)$ & $18(40.0)$ & \\
\hline$<5 \min$ & $217(18.7)$ & $36(36.0)$ & & $170(17.8)$ & $17(30.9)$ & & $47(22.8)$ & $19(42.2)$ & \\
\hline$<15 \min$ & $226(19.5)$ & $8(8.0)$ & & $183(19.2)$ & $7(12.7)$ & & $43(20.9)$ & $1(2.2)$ & \\
\hline Never had to hurry & $626(54.0)$ & $21(21.0)$ & & $533(55.9)$ & $14(25.5)$ & & $93(45.1)$ & $7(15.6)$ & \\
\hline $\begin{array}{l}\text { Experiencing fecal urgency } \\
\text { at least monthly }\end{array}$ & $100(8.6)$ & $58(58.0)$ & $<0.001$ & $70(7.4)$ & $30(54.5)$ & $<0.001$ & $30(14.6)$ & $28(62.2)$ & $<0.001$ \\
\hline Abdominal pain at least monthly & $234(20.2)$ & $48(48.0)$ & $<0.001$ & $181(19.1)$ & $26(47.3)$ & $<0.001$ & $53(25.7)$ & $22(48.9)$ & 0.008 \\
\hline
\end{tabular}

during the day. During sleep, however, conscious contraction to prevent unwanted loss of stool falls away, resulting in nocturnal FI. Second, we hypothesize that the anal-external sphincter continence reflex might be non-functional in some of these respondents. During their waking hours, patients with a non-functioning anal-external sphincter continence reflex are known to have trained themselves to respond to any rectal filling sensation by going to the toilet immediately, thus preventing FI. During asleep, however, this rescue system is inactive. Dysfunction of the anal-external sphincter continence reflex might be explained by nerve damage caused by surgery in the pelvic floor region or by comorbidities, such as diabetes mellitus.

Finally, we did not consider the obstetric history of women as a comorbidity because we recently showed that parity is not a risk factor for FI [21]. However, we did consider anal sphincter operation as a criteria to be assigned to the comorbidity subgroup. Furthermore, as demonstrated by Brusciano and others, it would be interesting to add clinical-functional measurements to demonstrate the underlying factors of FI in a follow-up study [22, 23].

\section{Limitations}

This study might be biased as a result of the low response rate of $54 \%$. This low rate may be explained by the nature of the topic and by the length of the questionnaire. We tried to limit response bias by creating a representative study group in which sex, region, and age were equally distributed in accordance with the population pyramid of the Netherlands. Furthermore, we formed the comorbidity subgroup on the basis of data reported by the respondents in the questionnaires and these data could not be validated against medical records because the questionnaires were anonymous. Anonymity was, however, helpful in obtaining honest answers to embarrassing questions on defecation habits.

\section{Conclusions}

The majority of the general Dutch population who suffer from FI report the combination of soiling and urge FI, while the minority report passive FI. Respondents who suffer from chronic diseases or who underwent pelvic floor or bowel surgery suffer from more severe forms of fecal incontinence. In contrast to the "healthy" subgroup, respondents in the comorbidity subgroup who suffered from FI felt urge sensation before defecating significantly less often than their fecally continent counterparts. This indicates that FI in this group might be caused by sensory nerve dysfunction. 
Acknowledgements The authors thank T. van Wulfften Palthe, $\mathrm{PhD}$, for correcting the English manuscript.

Authors' contributions Study concept, design and supervision: Broens Acquisition, analysis, and interpretation of data: van Meegdenburg, Meinds, Trzpis, and Broens

Drafting the manuscript: van Meegdenburg

Critical revision of the manuscript for important intellectual content: Meinds, Trzpis, and Broens

\section{Compliance with ethical standards}

Conflict of interest The authors declare that they have no conflict of interest.

Open Access This article is distributed under the terms of the Creative Commons Attribution 4.0 International License (http:// creativecommons.org/licenses/by/4.0/), which permits unrestricted use, distribution, and reproduction in any medium, provided you give appropriate credit to the original author(s) and the source, provide a link to the Creative Commons license, and indicate if changes were made.

\section{References}

1. Cotterill N, Norton C, Avery KN, Abrams P, Donovan JL (2008) A patient-centered approach to developing a comprehensive symptom and quality of life assessment of anal incontinence. Dis Colon rectum 51:82-87

2. Deutekom M, Dobben AC, Dijkgraaf MG, Terra MP, Stoker J, Bossuyt PM (2005) Costs of outpatients with fecal incontinence. Scand J Gastroenterol 40:552-558

3. Xu X, Menees SB, Zochowski MK, Fenner DE (2012) Economic cost of fecal incontinence. Dis Colon rectum 55:586-598

4. Bharucha AE, Dunivan G, Goode PS, Lukacz ES, Markland AD, Matthews CA, Mott L, Rogers RG, Zinsmeister AR, Whitehead WE, Rao SS, Hamilton FA (2015) Epidemiology, pathophysiology, and classification of fecal incontinence: state of the science summary for the National Institute of Diabetes and Digestive and Kidney Diseases (NIDDK) workshop. Am J Gastroenterol 110:127-136

5. Gee AS, Durdey P (1995) Urge incontinence of faeces is a marker of severe external anal sphincter dysfunction. Br J Surg 82:1179-1182

6. Vaizey CJ, Kamm MA, Bartram CI (1997) Primary degeneration of the internal anal sphincter as a cause of passive faecal incontinence. Lancet 349:612-615

7. Engel AF, Kamm MA, Bartram CI, Nicholls RJ (1995) Relationship of symptoms in faecal incontinence to specific sphincter abnormalities. Int J Color Dis 10:152-155
8. Ng KS, Sivakumaran Y, Nassar N, Gladman MA (2015) Fecal Incontinence: Community Prevalence and Associated Factors-A Systematic Review. Dis Colon Rectum 58:1194-1209

9. Meinds RJ, van Meegdenburg MM, Trzpis M, Broens PM (2017) On the prevalence of constipation and fecal incontinence, and their co-occurence, in the Netherlands. Int J Color Dis 32:475-483

10. Deutekom M, Dobben AC, Terra MP, Engel AF, Stoker J, Bossuyt PM, Boeckxstaens GE (2007) Clinical presentation of fecal incontinence and anorectal function: what is the relationship? Am J Gastroenterol 102:351-361

11. Munoz-Yague T, Solis-Munoz P, Ciriza de los Rios C, MunozGarrido F, Vara J, Solis-Herruzo JA (2014) Fecal incontinence in men: causes and clinical and manometric features. World J Gastroenterol 20:7933-7940

12. Bharucha AE, Zinsmeister AR, Locke GR, Schleck C, McKeon K, Melton LJ (2006) Symptoms and quality of life in community women with fecal incontinence. Clin Gastroenterol Hepatol 4: 1004-1009

13. Meinds RJ, van Meegdenburg MM, Trzpis M, Broens PM (2016) On the prevalence of constipation and fecal incontinence, and their co-occurrence, in the Netherlands. Int J Color Dis

14. Central Bureau for Statistics the Netherlands, www.statline.cbs.nl. Accessed 23-09-2016

15. Drossman DA, Chang L, Chey W, Tack J, Whitehead W (2016) Rome IV: the functional gastrointestinal disorders. Raleigh, NC, Rome foundation

16. Vaizey CJ, Carapeti E, Cahill JA, Kamm MA (1999) Prospective comparison of faecal incontinence grading systems. Gut 44:77-80

17. Jorge JM, Wexner SD (1993) Etiology and management of fecal incontinence. Dis Colon rectum 36:77-97

18. Broens PM, Penninckx FM, Ochoa JB (2013) Fecal continence revisited: the anal external sphincter continence reflex. Dis Colon rectum 56:1273-1281

19. van Meegdenburg MM, Heineman E, Broens PM (2015) Pudendal neuropathy alone results in urge incontinence rather than in complete fecal incontinence. Dis Colon rectum 58:1186-1193

20. Mimura T, Kaminishi M, Kamm MA (2004) Diagnostic evaluation of patients with faecal incontinence at a specialist institution. Dig Surg 21:235-41; discussion 241

21. van Meegdenburg MM, Trzpis M, Broens PMA, Fecal incontinence and parity in the Dutch population: a cross-sectional analysis, United European gastroenterology journal. Accepted for publication: DOI: https://doi.org/10.1177/2050640618760386

22. Brusciano L, Limongelli P, del Genio G, Sansone S, Rossetti G, Maffettone V, Napoletano V, Sagnelli C, Amoroso A, Russo G, Pizza F, Del Genio A (2007) Useful parameters helping proctologists to identify patients with defaecatory disorders that may be treated with pelvic floor rehabilitation. Tech Coloproctol 11:45-50

23. Brusciano L, Limongelli P, del Genio G, Rossetti G, Sansone S, Healey A, Maffettone V, Napolitano V, Pizza F, Tolone S, del Genio A (2009) Clinical and instrumental parameters in patients with constipation and incontinence: their potential implications in the functional aspects of these disorders. Int J Color Dis 24:961-967 